\title{
A Study on the Current Situation and Development Countermeasures of Traditional Sports Training of Minority in China
}

\author{
Zimin Chang, Shiqing Le \\ Nanchang Institute of Science \& Technology, Nanchang City, Jiangxi \\ Province, 330108, China
}

\begin{abstract}
China is a multi-ethnic country. Minority nationalities are the main components of Chinese sports. Carrying out the traditional sports of minority nationalities is the need for them to keep fit and inherit their excellent culture. In this paper, based on the authors' learning and practical experience, we first analyzed the current situation of traditional sports of minority nationalities, and then put forward the development countermeasures of traditional sports of minority nationalities. It is of great significance to deepen the exploitation of national traditional sports resources and cultural connotations, expand the sports and cultural exchanges of all nationalities, maintain the coordinated development of sports in different regions, promote the unity of all nationalities, and achieve common social progress.

Keywords: minority nationalities; traditional sports; training current situation; development countermeasures
\end{abstract}

\section{Introduction}

The traditional sports activities of minority nationalities formed after the longterm practice development in specific environmental areas and social life, which is related to national psychology, temperament, economy, culture, morality and social development, and is also associated with the living environment, festivals and celebrations, folk customs and practices of the local minority nationalities. It vividly displays the characteristics of agricultural national civilization[1]. Its 
excellent cultural elements can be inherited and developed via the excavation and arrangement of the traditional sports activities of minority nationalities, and maintenance of the characteristics of the national traditional sports culture.

\section{Development Status of Minority Nationalities Sports}

\subsection{Impact of modern civilization}

Traditional sports of minority nationalities are the product of agricultural civilization era. With the development of our country's society and economy, and the impact of western modern civilization, traditional sports of minority nationalities have gradually lost the foundation of survival and development. Since the reform and opening up, the levels of people's material and spiritual cultures have been greatly developed, which is rapidly changing the life style of people in minority nationalities areas. The past traditional sports, which the people of minority nationalities loved and enjoyed, gradually lost their charm, and are replaced by television, network, modern sports, outdoor sports and sports tourism. Traditional sports of minority nationalities have gradually moved away from the local people's life[2]. Most of them only exist in local festivals and traditional sports events of minority nationalities held by the government. The population participating in local traditional sports activities is less and less. The traditional sports of minority nationalities are faced with the danger of extinction. In addition, the input of western modern sports culture also poses a huge impact on the traditional sports of the minority nationalities. Currently, the majority of sports activities and sports events people participated in are modern sports, and traditional sports of minority nationalities have gradually become a kind of decoration. As early as the end of the nineteenth century, China has started the transformation of traditional sports, but with the strong impact of the Olympic sports, the development of traditional sports of minority nationalities is more and more difficult. Their faced difficulties are increasingly obvious.

\subsection{Lack of spiritual and cultural connotations}

The traditional sports of minority nationalities come from the productive labor of the working people. The minority nationalities have created a variety of traditional sports forms in their production practice. Most of the traditional sports of minority nationalities are closely linked with the productive labor, which are simple, and not limited by the venue equipment, age, gender, environment and climate. Besides, they usually use local materials, and are easy to popularize. The traditional sports of minority nationalities can not only effectively exercise the body, but also strengthen the national unity in the sports, and enhance the national cohesion, which play roles that other sports can substitute for.

In addition, these sports are the carriers of living habits, religious beliefs, values, and thinking mode of minority nationalities, reflect the cultural mental structure of the people of minority nationalities, have rich spiritual and cultural 
connotations, and are important parts of the study of minority nationalities culture. At present, most of groups do not pay much attention to the traditional sports culture of minority nationalities. The consciousness of protecting the intangible cultural heritage is weak[3]. Many people blindly chase western civilization and modern life style, and lack the sense of national identity and pride. Although the government attaches great importance to the development of the traditional sports of minority nationalities, most of them focus on its economic value, ignore the excavation of its spiritual and cultural connotations, and do not systematically and effectively protect the traditional sports of minority nationalities and their cultural soil.

\subsection{Loss and discontinuity of inheritance}

Traditional sports of minority nationalities have a strong regional character, and their occurrence, inheritance and development need specific soil. Most of the traditional sports of minority nationalities occur in relatively backward and closed soils. In the agricultural society, the backward mode of production and inconvenient traffic make the traditional sports of minority nationalities less influenced by external culture, and relatively effectively and naturally inherited inside. With the social development and the impact of foreign civilization, minority nationalities areas have gradually changed from relatively backward and closed to open. People's way of life has undergone tremendous changes, which makes the inheritance of traditional sports of minority nationalities faced with unprecedented difficulties[4]. With the process of urbanization, and the changes of cultural and natural ecology in minority nationalities areas, more and more young people go out to work, which makes the population inheriting traditional sports of the minority nationalities significantly decrease, and the soil they depend on gradually disintegrates.

With the impact of modern civilization, people's lifestyles and values in minority nationalities areas have undergone tremendous changes. The thinking and behavior mode of young people have already been alienated from the traditional sports of minority nationalities. They lack a certain understanding towards the traditional sports culture of minority nationalities, and have no consciousness of cultural heritage. The heritages of some traditional sports of minority nationalities adopt the oral way, which requires a certain amount of time and material guarantee. The survival pressure of modern young people is bigger and bigger. Few young people have cultural heritage consciousness, and consciously take up the heritage mission of the national traditional sports, which makes the traditional sports of minority nationalities faced with the risk of loss and discontinuity. 


\section{Development Countermeasures of Traditional Sports of Minority Nationalities}

\subsection{Carry forward the traditional sports of minority nationalities}

It is an important task to excavate the national traditional sports items in a comprehensive way, and develop national traditional sports items in a hierarchical manner. It is necessary to take into consideration both the overall situation and the different characteristics of different nationalities in different regions. For some national sports inherited from generation to generation, we should not only retain the core content of the heritage, but also promote their further development based on the real social culture, production mode and living conditions, which could make them more substantial and rich in content and form, evolution and extension at the cultural level, and expansion and enrichment in content[5]. In the course of abandoning and improving the specific content of ethnic sports, we should inherit the excellent cultural characteristics of traditional sports of minority nationalities, keep their national character, coordinate these sports terms with the real life and cultural conditions of ethnic groups, and actively absorb the essence of modern competitive sports to find their combination point.

\subsection{Improve the management system, and increase fund input}

Traditional sports of minority nationalities are important components of regional sports, and also a lucrative cultural resources. Therefore, it is the development tendency of traditional sports of minority nationalities to establish a kind of organization and management system according to the different ethnic customs and sports characteristics, which adapts to market economy conditions, and is macroscopically controlled by the government and operated by the various social groups. The financial difficulty is the main factor restricting the development of national traditional sports. The government at all levels should pay much attention to this problem, strengthen the investment in the field and equipment, and improve the hardware facilities of national sports[6]. At the same time, we should not ignore the talent construction, and should cultivate comprehensive sports management talents who not only are familiar with traditional sports of minority nationalities but also have management knowledge and are proficient in market management.

\subsection{Promote the protection of intangible cultural heritage}

With the process of modernization, the Chinese and western cultures continue to blend. Western modern sports has become the mainstream of mass sports. More and more people choose the introduced western sports. The development of 
traditional sports of minority nationalities have been gradually difficulty and marginalized. China has always attached great importance to the protection of cultural heritage and promote the excellent traditional culture. However, with the process of globalization, and continuous development of society and economy, China's intangible cultural heritage encountered many problems. In order to further strengthen the intangible cultural heritage protection work, the State Council issued "on strengthening the protection work of China's intangible cultural heritage". The traditional sports items of minority nationalities were included in the list of intangible cultural heritage, which can enhance the status and ownership of the traditional sports of minority nationalities in the intangible cultural heritage. Therefore, the traditional sports of minority nationalities can be better inherited and developed from the perspective of intangible cultural heritage via learning from measures and ideas of the intangible cultural heritage protection.

\subsection{Exploit cultural tourism resources of traditional sports of minority nationalities}

For tourists, in addition to watch the local scenery, they also hope to experience the local customs via exchange and participation to obtain emotional experience. Most of the gathering places of minority nationalities in China have good tourism environment and unique customs, which provides a good environment for the development of sports tourism. Traditional sports of minority nationalities have become one of the important parts of sports tourism, and have a broad development prospect. Traditional sports of minority nationalities have rich cultural connotations and regional customs. They can intuitively reflect the national cultural characteristics such as folk customs, costume culture, religious sacrifices, marriage customs, and festivals entertainment, which have strong property of participation, ornamentation and entertainment[7]. Therefore, it is necessary to fully exploit the tourism value of the traditional sports of minority nationalities, and realize the combination of traditional sports and sports tourism by allowing the tourists to watch the traditional sports performances or participate in sports, which can not only have the effect of promotion and dissemination, but also obtain a certain economic benefit.

\section{Conclusion}

Although there are still some problems in the development of national sports, China's traditional sports of minority nationalities have made great progress. In order to better develop the traditional sports of minority nationalities, we can start from the following aspects. First, carry forward minority sports. Second, improve the management system, and increase fund input. Third, promote the protection of intangible cultural heritage. Fourth, exploit cultural tourism resources of traditional sports of minority nationalities. 


\section{References}

[1] NI Dongye, LIU Shiying. The current situation and development countermeasures of minority nationalities' sports training base in Hubei. Journal of Hubei Nationalities Institutes (Philosophy and Social Sciences Edition), 02, pp.63-66, 2009.

[2] SHEN Lin, ZHU Meixin. The current situation and countermeasures of minority traditional sports in Xinjiang. Journal of Xinjiang Normal University (Natural Science Edition), 03, pp.26-32, 2009.

[3] HUANG Youjun, TANG Zhiyun. The current situation and development countermeasures of the minority nationalities' traditional sports items "Board Shoes Racing" in Guangxi. Journal of Baise University, 2008, 06: 95-97.

[4] WANG Qiong. The current situation and development countermeasures of minority traditional sports in Yunnan province. Journal of Chengdu Physical Education Institutes, 04, pp.45-47, 2011.

[5] LUO Shali, AI Kang, BIAN Ka. The current situation and development countermeasures of traditional sports training base for minority nationalities in Hainan province. Contemporary Sports Technology, 35, pp.119-120, 2013.

[6] LI Jun, LI Rong. The current situation and development countermeasures of minority nationalities' traditional sports in Guizhou province Sports Science and Technology Bulletin, 07, pp.105-106, 2014.

[7] QIU Yu. The current situation and development countermeasures of minority nationalities' traditional sports. Journal of Taishan University, 06, pp.100-103, 2016. 